\title{
Supporting Evidences To the Exact $\pi$ Value from the Works Of Hippocrates Of Chios, Alfred S. Posamentier And Ingmar Lehmann
}

\author{
R.D. Sarva Jagannadha Reddy \\ 19-9-73/D3, Sri Jayalakshmi Colony, S.T.V. Nagar, Tirupati - 517 501, A.P., India
}

\begin{abstract}
Till very recently we believed $3.1415926 \ldots$ was the final value of $\pi$.And no body thought exact $\pi$ value would be seen in future. One drawback with 3.1415926...is, that it is not derived from any line-segment of the circle. In fact, 3.1415926 ... is derived from the line-segment of the inscribed/ circumscribed polygon in and about circle, respectively. Surprisingly, when any line-segment of the circle is involved two things happened: they are 1. Exact $\pi$ value is derived and 2 that exact value differs from $3.1415926 \ldots$ from its $3^{\text {rd }}$ decimal onwards, being 3.1464466... Two geometrical constructions of Hippocrates of Chios, Greece (450 B.C.) and Prof. Alfred S. Posamentier of New York, USA, and Prof. Ingmar Lehmann of Berlin, Germany, are the supporting evidences of the new $\pi$ value. They are detailed below.
\end{abstract}

Keywords: $\pi$ value, lune, triangle, area of curved regions

\section{Introduction}

In the days of Hippocrates, $\pi$ value 3 of the Holy Bible was followed in mathematical calculations. He did not evince interest in knowing the correct value of $\pi$. He wrote a book on Geometry. This was the first book on Geometry. This book became later, a guiding subject for Euclid's Elements. He is very famous for his squaring of lunes. Prof. Alfred S. Posamentier and Prof. Ingmar Lehmann wrote a very fine collaborative book on $\pi$. They have chosen two regions and have proved both the regions, though appear very different in their shapes, still both of them are same in their areas. These areas are represented by a formula $r^{2}\left(\frac{\pi}{2}-1\right)$. The symbol ' $r$ ' is radius. $\pi$, here must be, the universally accepted $3.1415926 \ldots$

Every subject in Science is based on one important point. It would be its soul. In Geometry, the soul is a line-segment. The study of right relationship between two or more line-segments help us to find out areas, circumference of a circle, perimeters of a triangle, polygon etc. For example, we have side in the square, base, altitudein the triangle. The same concept is extended here, to show its inevitable importance in the study of two regions of Professors of USA and Germany. The lengths of the concerned line-segments have been arrived at and associated with $r^{2}\left(\frac{\pi}{2}-1\right) \cdot 3.1415926 \ldots$ does not agree with the value of line-segments of two regions. However, the new value $3.1464466 \ldots=\frac{14-\sqrt{2}}{4}$ has agreed in to-to with the line-segments of the two regions of the Professors. This author does believe this argument involving interpretation of $r^{2}\left(\frac{\pi}{2}-1\right)$ with the linesegments, is acceptable to these great professors and the mathematics community. It is only a humble submission to the World of Mathematics. Judgment is yours. If this argument in associating line-segment with the formula looks specious or superficial, this author may beexcused.

The two methods are as follows:

\section{Procedure}

\section{Hippocrates' Method of Squaring Lunes And Computation of The Exact $\pi$ Value}

"Archimedes's procedure for finding approximate numerical values of $\pi$ (without, of course, referring to $\pi$ as a number), by establishing narrower and narrower limits between which the value must lie, turned out to be the only practicable way of squaring the circle. But the Greeks also tried to square the circle exactly, that is they tried to find a method, employing only straight edge and compasses, by which one might construct a square equivalent to the given circle. All such attempts failed, though Hippocrates of Chios did succeed in squaring lunes.

Hippocrates begins by noting that the areas of similar segments of circles are proportional to the squares of the chords which subtend them 
Consider a semi-circle ACB with diameter AB. Let us inscribe in this semi-circle an isosceles triangle $\mathrm{ACB}$, and then draw the circular arc AMB which touches the lines $\mathrm{CA}$ and $\mathrm{CB}$ at $\mathrm{A}$ and $\mathrm{B}$ respectively. The segments ANC, CPB and AMB are similar. Their areas are therefore proportional to the squares of AC, CB and $\mathrm{AB}$ respectively, and from Pythagoras's theorem the greater segment is equivalent to the sum of the other two. Therefore the lune ACBMA is equivalent to the triangle ACB. It can therefore be squared".

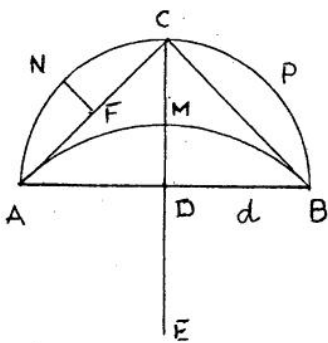

and $\mathrm{BCM}$ are devised.

The Circular arc AMB which touches the lines $\mathrm{CA}$ and $\mathrm{CB}$ at $\mathrm{A}$ and $\mathrm{B}$ respectively can be drawn by taking $\mathrm{E}$ as the centre and radius equal to $\mathrm{EA}$ or $\mathrm{EB}$.

$\mathrm{AB}=$ diameter, $\mathrm{d} . \quad \mathrm{DE}=\mathrm{DC}=$ radius, $\mathrm{d} / 2 ; \quad \mathrm{F}=$ mid point of $\mathrm{AC}$

$\mathrm{N}=$ mid point of arc $\mathrm{AC}$

$$
\mathrm{NF}=\frac{\sqrt{2} d-d}{2 \sqrt{2}} ; \quad \mathrm{DM}=\frac{\sqrt{2} d-d}{2} ; \mathrm{MC}=\frac{\sqrt{2} d-d}{\sqrt{2}}
$$

With the guidance of the formulae of earlier methods of the author where a Circle is inscribed with the Square, the formulae for the areas of ANC, CPB, ACM

1. Area of $\mathrm{ANC}=$ Area of $\mathrm{CPB}=2\left\{\frac{\mathrm{d}^{2}}{32}\left(1+\frac{\sqrt{2}-1}{2 \sqrt{2}}\right)\right\}$

2. Area of $\mathrm{AMB}=$ Areas of $\mathrm{ANC}+\mathrm{CPB}$ (Hippocrates)

3. Area of $A C M=$ Area of $B C M=\frac{\frac{(\sqrt{2} d)^{2}}{16}}{8\left(\frac{\sqrt{2}-1}{\sqrt{2}}\right)}$

4. Area of ACB triangle $=\frac{1}{2} \times \frac{\mathrm{d}}{2} \times \mathrm{d}$

5. According to Hippocrates the area of the lune ACBMA is equivalent to the area of the triangle $\mathrm{ACB}$

$$
\text { Lune ACBMA } \quad=\text { triangle } \mathrm{ACB}
$$

$(\mathrm{ANC}+\mathrm{ACM}+\mathrm{BCM}+\mathrm{CPB})$

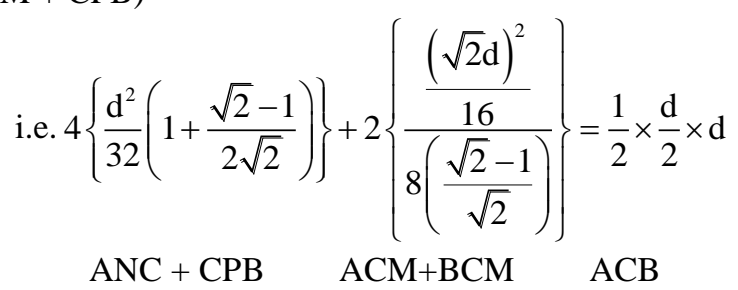

From the above equation it is clear that the devised formulae for the areas of different segments is exactly correct.

6. Area of $\mathrm{AMB}=$ Areas of $\mathrm{ANC}+\mathrm{CPB}$

7. Area of the semicircle $=\frac{\pi \mathrm{d}^{2}}{8}=$ Areas of $\mathrm{ANC}+\mathrm{CPB}+\mathrm{ACM}+\mathrm{BCM}+\mathrm{AMB}$

8. $\pi=\frac{8 \times \text { Area of the semicircle }}{\mathrm{d}^{2}}$

$=\frac{8}{\mathrm{~d}^{2}}\left[4\left\{\frac{\mathrm{d}^{2}}{32}\left(1+\frac{\sqrt{2}-1}{2 \sqrt{2}}\right)\right\}+2\left\{\frac{\frac{(\sqrt{2} \mathrm{~d})^{2}}{16}}{8\left(\frac{\sqrt{2}-1}{\sqrt{2}}\right)}\right\}+4\left\{\frac{\mathrm{d}^{2}}{32}\left(1+\frac{\sqrt{2}-1}{2 \sqrt{2}}\right)\right\}\right]=$

$$
\frac{14-\sqrt{2}}{4}
$$

\section{Alfred S. Posamentier's similarity of the two areas}

and decimal similarity between an area and its line-segments

Prof. A.S. Posamentier has established that areas of A and B regions are

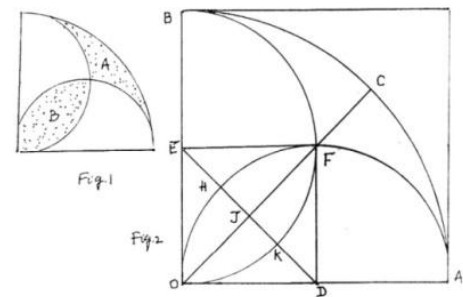


equal. His formula is $r^{2}\left(\frac{\pi}{2}-1\right)$ for the above regions. This author is grateful to the professor of New York for the reason through his idea this author tries to show that his new $\pi$ value equal to $\frac{1}{4}(14-\sqrt{2})$ is exactly right.

1. $\mathrm{Arc}=\mathrm{BCA} ; \mathrm{O}=$ Centre$; \mathrm{OB}=\mathrm{OA}=\mathrm{OC}=$ Radius $=\mathrm{r}$

2. Semicircles $: \mathrm{BFO}=\mathrm{AFO} ; \mathrm{E}$ and $\mathrm{D}=$ Centres $; \mathrm{OD}=\mathrm{DA}=\mathrm{BE}=\mathrm{OE}=$ radius $=\frac{r}{2}$

$\mathrm{OF}=\frac{\sqrt{2} r}{2} ; \mathrm{FC}=\mathrm{OC}-\mathrm{OF}=r-\frac{\sqrt{2} r}{2}=\frac{2 r-\sqrt{2} r}{2}$

3. $\quad$ Petal $=\mathrm{OKFH} ; \mathrm{EK}=\frac{r}{2} ; \mathrm{ED}=\frac{\sqrt{2} r}{2} ; \mathrm{EJ}=\frac{\sqrt{2} r}{4} ; \mathrm{JK}=\mathrm{EK}-\mathrm{EJ}=\frac{r}{2}-\frac{\sqrt{2} r}{4}=\frac{2 r-\sqrt{2} r}{4} ;$

$\mathrm{JK}=\mathrm{JH}, \mathrm{HK}=\mathrm{JH}+\mathrm{JK}=\frac{2 r-\sqrt{2} r}{2}$

4. So, $\mathrm{FC}$ of region $\mathrm{A}=\mathrm{HK}$ of region $\mathrm{B}=\frac{2 r-\sqrt{2} r}{2}$

5. $\quad B F A C=$ OKFH i.e. areas of $A$ and B regions are equal (A.S. Posamentier and I. Lehmann).

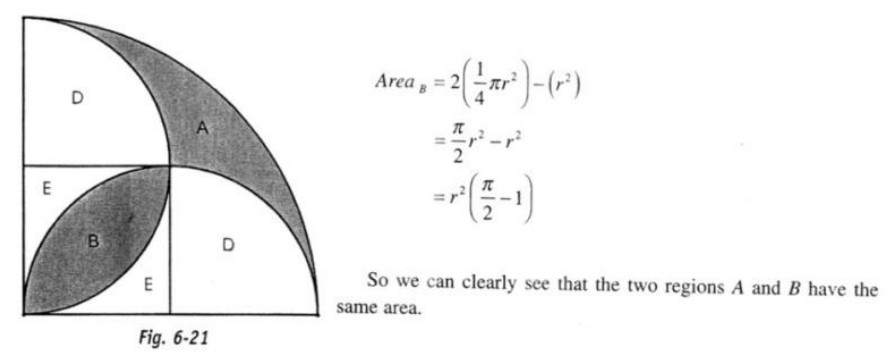

(By Courtesy: From their book )

Formula for A and B is $r^{2}\left(\frac{\pi}{2}-1\right)=\frac{r^{2}}{2}(\pi-2)$

Here $\mathrm{r}=$ radius $=1$

From March 1998, there are two $\pi$ values. The official $\pi$ value is $3.1415926 \ldots$ and the new $\pi$ value is $\frac{14-\sqrt{2}}{4}=3.1464466 \ldots$ and which $\pi$ value is exact and true ?

Let us substitute both the values in $\frac{r^{2}}{2}(\pi-2)$, then

Official $\pi$ value $=\frac{r^{2}}{2}(3.1415926-2)=\frac{r^{2}}{2}(1.1415926 \ldots)$

(It is universally accepted that $3.1415926 \ldots$ is approximate at its last decimalplace however astronomical it is in its magnitude.)

New $\pi$ value $=\frac{r^{2}}{2}(3.1464466-2)=\frac{r^{2}}{2}(1.1464466 \ldots)$

6. $\mathrm{FC}=\mathrm{HK}(\mathrm{HJ}+\mathrm{JK})$ line segments $=\frac{2 r-\sqrt{2} r}{2}$

7. Half of $\mathrm{HC}$ and $\mathrm{HK}$ are same $\frac{F C}{2}=\frac{H K}{2}=\left(\frac{2 r-\sqrt{2} r}{2}\right) \frac{1}{2}=\frac{2 r-\sqrt{2} r}{4}=\mathbf{0 . 1 4 6 4 4 6 6 \ldots . . .}$

8. Area of A/B region equal to $1.1464466 \ldots$ is similar in decimal value of half of $\mathrm{FC} / \mathrm{HK}$ line segment i.e. $0.1464466 \ldots$

9. Formulae $\mathrm{a}^{2}, 4 \mathrm{a}$ of square and $1 / 2 \mathrm{ab}$ of triangle are based on side of the square and altitude, base of triangle, respectively. In this construction, FC and HK are the line segments of A and B regions, respectively. 
As the value $0.1464466 \ldots$ which is half of FC or HK is in agreement with the area value of A/B region equal to $1 . \underline{1464466} \ldots$ in decimal part, it is argued that new $\pi$ value equal to $\frac{1}{4}(14-\sqrt{2})=3.1464466 \ldots$ is exactly correct.

The decimals $0.1415926 \ldots$ of the official $\pi$ value $3.1415926 \ldots$ does not tally beyond $3^{\text {rd }}$ decimal with the half the lengths of $\mathrm{HK}$ and FC, whose value is $0.14 \underline{64466}$, thus, the official $\pi$ value is partially right. Whereas, FC $\&$ HK are incompatible with the areas of A \& B calculated using official $\pi$ value. Then, which $\pi$ is real, Sirs?

\section{Conclusion}

$3.1415926 \ldots$ agrees partially (upto two decimals only) with the line-segments of curved geometrical constructions. When these line-segments agree totally and play a significant role in these constructions a different $\pi$ value, exact $\pi$ value $\frac{14-\sqrt{2}}{4}=3.1464466 \ldots$ invariably appears. Hence, $\frac{14-\sqrt{2}}{4}$ is the true valueof $\pi$.

\section{Acknowledgements}

This author is greatly indebted to Hippocrates of Chios, Prof. Alfred S. Posamentier, and Prof. Ingmar Lehmann for using their ingenious and intuitive geometrical constructions as a supportive evidence of the new value of $\pi$.

\section{Reference}

[1]. T. Dantzig (1955), The Bequest of the Greeks, George Allen \& Unwin Ltd., London.

[2]. P. Dedron and J. Itard (1973). Mathematics and Mathematicians, Vol.2, translated from French by J.V. Field, The Open University Press, England.

[3]. Alfred S. Posamentier\&Ingmar Lehmann (2004). $\pi$ A Biography of the World's Most Mysterious Number. Prometheus Books, New York, Pages 178 to 181 .

[4]. RD Sarva Jagannadha Reddy (2014), Pi of the Circle, a Canto on-line edition, in the free website: www.rsjreddy.webnode.com 